\title{
La profesión y oficio de vidriero en los siglos XV y XVI: Talleres, encargos y clientes
}

\author{
Víctor Nieto AlCAide*
}

\begin{abstract}
RESUMEN
ABSTRACT

Estudio de la profesión y trabajo de los

Study about the glass painters in Spain vidrieros en España durante los siglos in the fefteenth and sixteenth $x \vee y \times v i$. Se estudian los encargos, las centuries. The work of theese distintas operaciones como el empleo craftsmen, his status and the relations

$y$ difusión de los cartones, los encargos, los problemas de competencia, la organización de los talleres y la consideración de los between the artist and the patrons. His worshops in the towns and in the cathedrals. Glass, cartoon, grisaille and painting.
\end{abstract} vidrieros en esta época.

\section{ARTISTAS DEL FUEGO}

La evolución de la vidriera y la actividad de los vidrieros se ha desarrollado siempre en relación con un fenómeno que ha condicionado su existencia: la extrema fragilidad del vidrio. Debido a las funciones de cierre que cumple en el edificio, la vidriera ha estado siempre sometida a pérdidas y alteraciones que han condicionado la labor de los vidrieros de una manera decisiva hasta el punto de que, desde sus orígenes, su actividad ha discurrido por una doble vía: crear y restaurar para conservar.

\footnotetext{
* Departamento de Historia del Arte. UNED
} 
El comportamiento de los vidrieros, además, debido al escenario y a las condiciones en que se desarrolla su arte ha seguido siempre unas pautas muy particulares. Si en otras actividades artísticas la técnica ha tenido unas repercusiones secundarias, en la vidriera ha sido siempre un problema fundamental. Los problemas de asentamiento, el complejo proceso de ejecución de las obras, la organización del taller, la complejidad y fragilidad de un material como el vidrio sitúan la actividad de los vidrieros en un espacio intermedio entre un artesano poseedor de una experiencia empírica y un estudioso de los materiales y los procesos para transformarlos. Artistas obsesionados por los problemas técnicos y las dificultades de la ejecución, los vidrieros, al margen del valor plástico de sus obras, han desarrollado una actividad planteada como un diálogo permanente con dos elementos mágicos y fascinantes: el vidrio y el fuego. La paleta del vidriero, formada en principio por los colores que tiene el vidrio en su masa, presenta un cromatismo limitado. Pero a través del juego y combinación de los vidrios, de su formato y disposición, del control de la luz mediante la grisalla, el amarillo de plata y los esmaltes, los vidrieros han obtenido una gama de registros plásticos inagotables.

Esta condición de artistas del fuego no ha impedido nunca a los vidrieros llevar a cabo una labor en sintonía con los desarrollos artísticos de cada época pero ha determinado una forma particular y diferenciada de sentir y vivir el hecho artístico. La practicidad y el empirismo de los vidrieros durante la Edad Media, sus preocupaciones por los problemas del «oficio» como parte inseparable de la creación, no diferenció el status y la estima de los vidrieros de la que poseían otros artistas. Fue, en el Renacimiento cuando se produjo una fractura debida a la obligada atención por los problemas técnicos que exigía la labor del vidriero en un momento en el que los artistas iniciaban el abandono de su condición de artesanos.

En la vidriera el proceso de ejecución, la realización, el empleo de los cartones y el paso de un boceto realizado sobre un soporte opaco a un material traslúcido, han condicionado profundamente la labor de sus autores. Los vidrieros, aunque siempre han estado en conexión con el arte de su tiempo - unas veces, como innovadores; otras, como seguidores de formas creadas por otras artes; las más, como artistas que realizan una labor en solitario aunque paralela e integrada en las corrientes artísticas del momento- han seguido siempre unas pautas propias. Incluso en aquellas etapas, como en los siglos $X V$ y XVI, en los que, como se ha dicho repetidas veces, la vidriera "imita la pintura", los vidrieros han desarrollado siempre un lenguaje diferenciado y propio ${ }^{1}$. Los vidrieros han podido 
utilizar unos mismos modelos, desarrollar formas y planteamientos similares desde un punto de vista figurativo $u$ ornamental a los de los pintores, miniaturistas, escultores u orfebres. Pero la condición traslúcida del vidrio ha exigido siempre la aplicación de unas soluciones específicas y propias de la vidriera. Resultados en los que, como en todas las artes del fuego, el azar y lo casual han jugado un papel importante determinando profundamente el trabajo de los vidrieros. De ahí, que la colaboración entre pintores y vidrieros no haya sido tan estrecha como se ha supuesto.

La descripción del proceso de realización de una vidriera transmitida por Cennino Cennini en su Libro del Arte responde básicamente a las recomendaciones de un pintor a otro pintor ${ }^{2}$. Pues, la división del trabajo, basada en el sistema de un pintor que "crea» y el vidriero que "ejecuta", fue algo que se produjo con una especial intensidad en el mundo artístico italiano. En obras conservadas en las que consta documentalmente la intervención de un pintor como el creador del modelo, como, por ejemplo, la vidriera del Noli me tangere de la Capilla Bautismal de la Catedral de Barcelona, puede comprobarse este fenómeno. Consta documentalmente, que la vidriera fue ejecutada por Gil Fontanet en 1495, siguiendo una traza del pintor Bartolomé Bermejo ${ }^{3}$. En la vidriera nada puede apreciarse que ponga de manifiesto una traducción del arte del pintor. Cuando los pintores suministraban modelos eran bocetos desde los que el vidriero realizaba el cartón a escala reducida o proyecto para luego proceder a la ejecución del cartón a escala natural. Una vidriera nunca es la traducción sobre un soporte de vidrio de una pintura, sino que, aunque parta de ésta, requiere un tratamiento especifico que exige "pensar en vidrio". Lo cual resultaba imposible llevar a cabo sin una práctica en la técnica de la vidriera.

Arnao de Vergara y Arnao de Flandes, en el contrato celebrado el 22 de diciembre de 1534 con el cabildo de la catedral de Sevilla, se comprometían a presentar, antes de iniciar la realización de la vidriera, un modelo sobre el que el cabildo podría realizar las sugerencias que estimase oportunas pero con la condición de “... que sea cosa que en vydrio se pueda azer» ${ }^{4}$. A la complejidad de los procedimientos se debe

Cennino, C., El Libro de Arte. Madrid. Akal. 1988. Cap. CLXXI, págs. 211-212.

TORMO Y MON7O, E., "Bartolomé Bermejo, el más recio de los primitivos espan̄oles". Archivo Español de Ante, 1925, págs., 11-94; NIE 10 AlCAII, $V$. La vidriera del Renacimiento en España. Madrid. C. S. I. C., 1970 págs. 24 y ss. Ainaud de LASARTE, J. y otros. : C. V. M. A. España vol. 9. Catalunya vol. 4. Els vitralls de la catedral de Barcelona i del Monestir de Pedralbes. Barcelona. Institut D'Estudis Catalans, 1997, págs. 22-23.

Nie to Alcallt., V., C.V.M.A., España vol. I. Las vidrieras de la catedral de Sevilla. Madrid C. S. I. C., 1969, Doc. IV, 18, pág. 209 
el que fueran pocos los vidrieros preocupados por practicar otra actividad y que artistas de otras especialidades, salvo la realización de modelos, tengan una actividad en el campo de la vidriera. Sabemos que Arnao de Vergara era tambien miniaturista y que el 21 de marzo de 1532 formaba compañía con el iluminador Andrés Ramírez figurando como "yluminador e maestro de fazer vedrieras ${ }^{5}$. También tenemos noticia de algún vidriero, como Juan del Campo, que trabajó como entallador en el Palacio de Carlos $V$ de Granada ${ }^{6}$ y que Nicolás de Vergara el Viejo, que recibió una formación de vidriero en el taller familiar, fue tambien escultor, pintor, rejero y arquitecto ${ }^{7}$. Pero, éste fue un caso excepcional. Por lo regular, las menciones relativas a otras actividades desarrolladas por los vidrieros prueban que tenían un carácter secundario y circunstancial, como, por ejemplo, la realización, y reparación de viriles para custodias ${ }^{8}$.

Todo esto tuvo consecuencias en la consideración relativa del ejercicio mismo de la profesión. En el siglo XVI, cuando se perfila una nueva figura de artista, la vidriera iniciaba un proceso casi de extinción debido a su escasa o nula incidencia en la arquitectura clasicista. En el ambiente artístico español de esta centuria, los vidrieros desarrollaron una intensa labor hasta la década de los años sesenta, manteniendo un status que se correspondía con el de otros artistas. Sin embargo, los condicionantes del oficio y de los procedimientos, hacen suponer que el camino hasta la consideración de los vidrieros como "artistas liberales" habria estado plagado de dificultades. Además, cuando comenzaba a producirse el paso de artesano a artista, con maestros con una formación y personalidad como Nicolás de Vergara la vidriera era un arte que comenzaba a perder su vigencia. Por ello, los vidrieros no «entraron», y apenas se plantearon, el problema de la condición liberal de su profesión.

\section{ITINERARIOS Y TALLERES}

La complejidad de procedimientos y operaciones que requería la realización de vidrieras, así como la diversidad de encargos, exigía la existen-

\footnotetext{
Nieto Alcaide, V., 1969, Doc. IV, 13, pág. 208.

Gallego Burin, A., "Documentos relativos al entallador y vidriero Juan del Campo". Cuadernos de Arte, I, 1936, págs. 344-345

Marias, F., La Arquitectura del Renacimiento en Toledo. Toledo. Instituto Provincial de Investigaciones y Estudios Toledanos, 1983-1986, Vol. I, págs. 361-375

8 Nieto Alcaide, V., 1969, Doc. 14, pág. 203, Doc. VII, 1, pág. 236; Doc. VII. 19, pág. 237; Doc. VII, 22, pág. 237, Doc. VIII, 9, pág. 244
} 
cia unos talleres y una organización del trabajo diferentes para cada caso. Con frecuencia, los vidrieros acreditados poseian su propio taller como ponen de manifiesto las frecuentes menciones que hacen referencia al "maestro" y sus "oficiales". Maestros y oficiales realizaban las vidrieras en el taller y se desplazaban a los edificios para su asentamiento o establecían un taller provisional junto a éstos hasta dar por concluida la obra. Pero, a veces, especialmente en los primeros tiempos del gótico, muchos vidrieros no tenian un taller fijo en una ciudad, sino que eran artistas itinerantes que se establecían junto a los edificios para los que se les había realizado el encargo. Este fue el procedimiento seguido en la catedral de León en la segunda mitad del siglo xill cuando se inició el programa de las vidrieras a cargo de talleres formados en las soluciones de la vidriera francesa de poco antes de 1250 y que llegarian junto con otros artistas, como canteros y escultores, que trabajaron en la catedral. A este respecto, en 1277 Alfonso $X$ eximia de impuestos a veinte canteros, un herrero y un vidriero mientras trabajasen en la obra de la catedral ${ }^{9}$. Durante el siglo XIII, estos talleres tuvieron un carácter esencialmente itinerante. El vidriero, incluso en el caso de que tuviese taller establecido en una ciudad, era un homo viator ${ }^{10}$ que se trasladaba de catedral en catedral, de iglesia en iglesia, para buscar y realizar los encargos. Lo cual explica la abundancia de vidrieros procedentes de otros paises que trabajan en España. En este sentido, las noticias documentales prueban una crecida nómina de artistas extranjeros que importaron diferentes soluciones técnicas y formales integradas en el discurso de las corrientes internacionales. En 1325 trabajaba en Palma de Mallorca el vidriero Matteo di Giovanni que ejerció una importante influencia en la penetración de las soluciones trecentistas en la pintura mallorquina ${ }^{11}$. Igualmente, la llegada de artistas extranjeros jugó un papel decisivo en el desarrollo de la vidriera del Gótico Internacional. Entre 1357 y 1359, figura trabajando en las catedrales de Gerona y Tarragona, el vidriero alemán, Guillem Letumgart ${ }^{12}$. Desde 1397, en que aparece trabajando en la catedral de Lérida, figura Nicholi de Maraya, vidriero francés procedente de Troyes que extiende su labor por Cataluña, reali-

Garcia Villada, Z.. Cátalogo de códices y documentos de la catedral de León.. Madrid, 1919. núm. 1. 126

Casielnuovo, E., "El artista", en VV. AA. El Hombre Medieval. Madrid. Alianza Editorial. 1987, págs. 221 y ss.

Durliat, M., LArt en el Regne de Mallorca. Mallorca. Editorial Moll, 1964, pág. 275.

Ainaud, J. y otros, CV. M. A. España vol. 7. Catalunya vol. 2. Els vitralls de la catedral de Girona. Barcelona. Institut d'Estudis. Catalans. 1987. págs. 32-33; C.V.M.A. España vol. 8. Catalunya vol. 3. Els vitralls del Monestir de Santes Creus i de la Catedral de Tarragona. Barcelona. Institut d’Estudis Catalans. 1992, pág. 201. 
zando vidrieras en Barcelona, Santa Coloma de Queralt y Cervera ${ }^{13}$. En 1424, figura en la catedral de León Juan de Arquer o Angers, y, en esta misma década, realizan vidrieras en la catedral de Toledo los vidrieros Jacobo Dolfin y Luis Coutin, probablemente tambien franceses. Y en León, la presencia de Nicolás Francés, pintor que realizó bocetos y vidrieras para la catedral, desempeñó un papel decisivo en la importación de las soluciones del Internacional ${ }^{14}$. Igualmente por esos años es sensible la presencia de vidrieros extranjeros en Navarra como Girart, Copin Van Gant y Jacobo de Utrech ${ }^{15}$ y en Cataluña y Aragón donde trabaja Thierry de Mes (o Metz) que, entre 1448 y 1465 , realizaba vidrieras para la Seo de Zaragoza y la Casa Consistorial de Barcelona ${ }^{16}$.

En la vidriera española posterior los artistas extranjeros continuaron desempeñando un papel relevante. Es el caso de Antonio Llonye que, en 1460, trabajaba en las vidrieras de Santa Maria del Mar de Barcelona, que también trabajó en Toulouse, y a quien se menciona en 1462 en Avigliana, en la diócesis de Tori (Piamonte) ${ }^{17}$. Pero fue a finales del siglo $x \vee$ cuando esta afluencia de artistas extranjeros se hace patente influyendo decisivamente en el desarrollo de la vidriera integrada en el sistema de representación flamenco. Es el caso, del vidriero, procedente de Avignon Severi Desmasnes, que trabajó en las vidrieras de Santa Maria del Mar de Barcelona ${ }^{18}$. Y, de forma más relevante, de Enrique Alemán, vidriero formado en círculos alsacianos que, entre 1478 y 1491, trabajó para el Cardenal Don Pedro González de Mendoza en las catedrales de Sevilla y Toledo ${ }^{19}$ y en el Colegio de Santa Cruz de Valladolid ${ }^{20}$, y que desempeñó un papel fundamental en la introducción del sistema de representación flamenco en la vidriera española. A principios del siglo XVı hallamos, proce-

Duran I Sampere, A., Llibre de Cervera. Barcelona. Editorial Curial., 1977

Sanchilz Cantón, F. J.. Maestre Nicolás Francés. Madrid. C.S.I.C.. 1964: Nit to Al CAldf. V. La vidriera medieval. "Cuadernos de Arte Español». Madrid. Historia 16. 1993, pág. 21.

Martinez de Agulare, J., Arte y monarquia en Navarra. 1328-1425. Navarra. Institución Príncipe de Viana. 1987, pág. 348

LACARRA DYCAY, M. C., "La catedral metropolitana de Zaragoza", en VV.AA. Las Catedrales de Aragón. Zaragoza, 1987, pág. 318.

AINAUD de LASAATE, J., y otros, C.V.M.A. España vol 6. Catalunya vol 1. Els vitrralls medievals de leglesia de Santa Maria del Mar a Barcelona. Barcelona. Institut d'Estudis Catalans, 1985. págs. 18-19.

AinaUd dE LASARIt, J., y otros., 1985, págs. 199 y ss.

NiEto Alcaide, $V$., "Sobre la formación de Enrique Alemán, un vidriero alsaciano en la España de los Reyes Católicos", Boletín de la Real Academia de la Historia, 1967, págs. 37-42; "El maestro Enrique Alemán, vidriero de las catedrales de Sevilla y Toledo". Archivo Español de Arte, 1967, págs. 55-82.

San Roman, F. D. B., "Las obras y los arquitectos del Cardenal Mendoza", Archivo Español de Arte y Arqueologia, 1931, pág. 155. 
dente de Portugal, trabajando en la catedral de Sevilla, después de haberlo hecho en la de Santiago de Compostela, al flamenco Juan Jacques, natural de Zelanda ${ }^{21}$.

Aunque este carácter itinerante nunca se perdió, al final de la Edad Media cada vez fueron más frecuentes los talleres establecidos en las ciudades. Lo cual no impidió, por otra parte, que durante el siglo XVI, fueran numerosos los artistas procedentes de los Países Bajos que trabajaron en España como Gualter de Ronch, Pierres de Holanda y Pierres de Chiberri, Teodoro de Holanda, Enrique de Broecq, Carlos de Brujas o Vicente Menardo.

Desde finales del siglo $x v$ se formaron en Burgos varios talleres - como el de Arnao de Flandes el Viejo, Diego de Santillana y Juan de Valdiviesoque realizaron vidrieras para algunos de los principales edificios, tanto antiguos como modernos, de esta ciudad y de León, Palencia, Ávila, Oviedo o Santiago de Compostela. Con frecuencia, estas vidrieras, al igual que lo que sucedía con los retablos de pintura o escultura, eran realizadas en el taller de origen y luego transportadas hasta el edificio para el que habian sido encargadas. Este fue el procedimiento que siguió Diego de Santillana en la realización de vidrieras para edificios de ciudades alejadas de Burgos, como la catedral de Oviedo. en la que el 11 de abril de 1509 se le hacia un pago con motivo de que "...las dichas vidrieras heran venidas" "2. Para los trabajos de asentamiento el maestro se desplazaba al lugar en que tenian que ser colocadas las vidrieras, quedando el comitente obligado a facilitar alojamiento al maestro y sus ayudantes, como figura en el contrato. En el contrato firmado el 17 de diciembre de 1512 por Diego de Santillana con el Cabildo de la catedral de Palencia, éste se comprometía «... de le dar casa e posada, do esté el dicho Santillana e sus oficiales» ${ }^{23}$. Y cuando Juan Jacques reemprende la continuación del programa de las vidrieras de la catedral de Sevilla el cabildo acuerda, el 4 de noviembre de 1510, «...dar una camara al vedriero que faze las vidrieras" ${ }^{24}$.

Pero cuando las vidrieras eran realizadas in situ, el comitente estaba obligado a facilitar a los vidrieros un obracior donde realizar su trabajo

Nifto Alcaide, V., 1969, pág. 78.

Caso Fernandez. F. De, Colección documental sobre la catedral de Oviedo. // (1300-1520) Gijón. 1982, pág. 104. Otro pago, tambien en la catedral de Oviedo, le es efectuado a Diego de Santillana" por una caxa que la iglesia tomó de vidrieras". Caso Fehnandez, F. DF, 1982, Doc. 148, pág. 106.

Garcia Cuesta, T., "Las vidrieras pintadas de la catedral de Palencia" Boletin del Seminario de Estudios de Arte y Arqueologia de la Universidad de Valladolid, XXV, 1959, Doc. 4, pag. 80

2.4 Nieto Alcaide, V., 1969, Doc. III 4, pág. 203. 
según confirman algunas noticias documentales como el contrato celebrado entre el cabildo de la catedral de Palencia y los vidrieros Arnao de Flandes (el Viejo) y Juan de Valdivieso, el 6 de septiembre de 1503, para realizar vidrieras para el crucero, en el que se ordena que se les dé «...una casa do labren" 25. Sabemos por un documento del 31 de mayo de 1507 , relativo a la realización de las vidrieras de La Librería de la Catedral de León por Diego de Santillana, que se acordó «...aposentar al vidriero e darle lugar donde labre» junto con los ayudantes que había llevado para realizar este trabajo ${ }^{26}$. Este obrador fue el lugar en que se realizaban las vidrieras; pero cuando habían sido hechas en el taller de origen fue el sitio donde se ajustaban y reparaban en caso de haber sufrido algún desperfecto durante el transporte.

Junto a los vidrieros que, según hemos visto, formaban «la plantilla fija del taller», las contrataciones ocasionales para la realización de trabajos concretos fueron frecuentes como pone de manifiesto un pago, realizado, en la catedral de Sevilla en 1554 a Arnao de Flandes «...por cinco días que ocupó dos hombres adereçando las vidrieras de la linterna de la Sacristía nueva" ${ }^{27}$. En cambio, para atender encargos de cierta magnitud se recurrió frecuentemente a la formación de compañia o asociaciones entre dos o más vidrieros y sus respectivos talleres. Es el caso de Diego de Santillana Juan de Valdivieso y Arnao de Flandes (el Viejo) que realizan encargos de esta manera. O el de Arnao de Vergara y Arnao de Flandes por este procedimiento "de mancomún" en las vidrieras de la catedral de Sevilla, según el contrato,del 22 de diciembre de $1534^{28}$, o de los flamencos Pierres de Holanda y Pierres de Chiberri ${ }^{29}$ en la catedral de Segovia. En realidad, este sistema no introducía variantes en el trabajo de taller. Solamente ampliaba sus posibilidades ante las exigencias de encargos de evergadura y proporcionaba una asociación entre talleres distintos para lograr un mayor número de encargos.

Los talleres fueron además, al igual que en otras especialidades, el núcleo aglutinador en el que se experimentaban técnicas y planteamientos artísticos que configuraban las diversas formas de "hacer vidriera". Los distintos componentes de un taller, a veces especializados en determina-

Garcia Cuesta, T., 1959, pág. 78.

26 Merino Rubio, W., Arquitectura hispanoflamenca en León. León. Institución Fray Bernardino de León. 1974, pág. 60.

NiE1O AlCAide. V., 1969, Doc. V, 227. pág. 137

28 Nieto Alcaide, V., 1969, Doc. IV, 18, pág. 209.

2 MARQUÉS DE LOzOYA, "Las vidrieras "Quinientistas" de la catedral de Segovia". Archivo Español de Arte, 1949, págs. 193-206; NIE IO Al.CAlDE, V. 1970 
dos trabajos, eran artistas que habian asumido "el estilo" o maniera creada e impuesta por el maestro y que marcaba las directrices del taller. Acerca de cómo eran estos talleres tenemos algunas noticias referentes al utillaje existente en ellos. En el inventario de los bienes de Nicolás de Vergara el Viejo, realizado por su hijo Nicolás de Vergara el Mozo el 10 de noviembre de $1574{ }^{30}$, se describen con precisión algunos de los utensilios y materiales existentes en el taller del vidriero. Vergara tenía vidrios blancos, vidrios bañados de colores, brochetas, lavadores, punzones, tenacillas, moldes, cascos, linternas, hilo de conejo, clavos, palmos de hierro "de medir", reglas, compases, cepillos, alicates, pinturas "en una cajuela" y varios cartones preparatorios. Es decir, vidrios blancos a los que pintar con grisalla, amarillo de plata y sanguina, vidrios esmaltados, especialmente los rojos plaqués, punzones para realizarlos enlevés, vidrios de ciba, hilo de conejo para realizar las redes de protección y otros utensilios.

Durante siglos la formación en el taller fue la única forma de aprendizaje. Los futuros vidrieros iniciaban esta formación siendo muy jóvenes como ponen de manifiesto algunas noticias como una del 13 de julio de 1538, según la cual Arnao de Vergara, que trabajaba como vidriero en la catedral de Sevilla, tomó "...de aprendiz por 8 años a Alonso de Narvaez" ${ }^{31}$ Estos contratos con frecuencia podian cancelarse; así el 3 de septiembre de 1537, Arnao de Vergara «...desiste y cancela la escritura de aprendizaje con Desiderio Tahellion por disgusto" ${ }^{32}$.

También fueron muy frecuentes los talleres familiares en los que el conocimiento del oficio se transmitía de padres a hijos. Son numerosos los casos de hijos de vidrieros que siguieron la misma profesión que sus padres y que realizaron, como es lógico, su formación en los talieres familiares como Arnao de Flandes y Arnao de Vergara, en el de su padre Arnao de Flandes el Viejo; Francisco de Valdivieso en el de Juan de Valdivieso; Nicolás de Holanda en el de su padre Alberto de Holanda; Nicolás de Vergara el Viejo en el de Arnao de Vergara o Nicolás de Vergara el Mozo en el de Nicolás de Vergara el Viejo. Todos elios se formaron en los talleres familiares colaborando en sus años de juventud en diversos encargos hasta que se independizaron o hicieron cargo del taller familiar y que hace difícil rastrear la obra inicial de muchos de estos vidrieros identificada formalmente con el "estilo» paterno. La relación profesional iniciada en el taller familiar solía prolongarse después de que al-

Marias, F., 1983. I, pág. 364.

Nieto Al.caide, V., 1969, Doc. V, 50, pág. 214.

Nieto Alcaide, V., 1969, IV, Doc. IV. 47, pág. 214. 
gunos de sus miembros se hubieran independizado. Algunos encargos, como el que recibe Arnao de Vergara cuando estaba en Granada de realizar una vidriera en la catedral de Segovia, por mediación de Nicolás de Vergara, acreditan como los vidrieros mantenían con frecuencia la cohesión del taller familiar aún después de haberse dispersado algunos de sus miembros. Igualmente son numerosos los ejemplos que ponen de manifiesto como el taller seguía funcionando a la muerte del vidriero, bajo la dirección de un oficial o la viuda del maestro. A la muerte de Arnao de Flandes, el 22 de noviembre de 1557, se medía, para proceder a su pago, la vidriera de La Venida del Espíritu Santo "...que dio fecha la mujer de Arnao de Flandes" 33.

La formación adquirida en el taller tenía básicamente un carácter práctico y técnico en relación con las dificultades y "secretos" del oficio. Pero, también, en el taller se producia el contacto con formas, tratados, modelos y obras que marcarian definitivamente la orientación artística del vidriero. La colección de objetos que tenia Nicolás de Vergara el Viejo, entre los que figuraban, modelos, lienzos, estampas, dibujos y trazas, tratados, pinturas, y esculturas, ponen de manifiesto como en los talleres existian obras que podían servir de referencia y de modelo y que han hecho pensar en la posibilidad de que Nicolás de Vergara realizase un viaje a Italia donde pudiera adquirir algunas de ellas ${ }^{34}$. Aunque la tónica general de todos los talleres no fuera esta, tampoco debe suponerse que en ellos se realizó exclusivamente una pura y simple labor práctica de ejecución. Si Vergara tenía estos modelos no cabe tampoco descartar que otros vidrieros, no menos interesados que él por las formas y soluciones del clasicismo, tuvieran objetos similares. La existencia en los distintos talleres de cartones a escala reducida, grabados y dibujos fue un material que se utilizaba para la ejecución de vidrieras, pero que cumplió una función no menos importante en la formación y el aprendizaje de los vidrieros.

\section{VIDRIEROS. ENCARGOS Y CLIENTES}

La ejecución de una vidriera, un programa completo o simples trabajos de conservación, exigian previamente la realización de una memoria o presupuesto. Asi consta en un pago a Arnao de Vergara de

\footnotetext{
Nit 10 AlCaide, V, Doc. V199, pág. 232

Marias, F, 1983, I, págs. 364-366.
} 
1537, en la catedral de Sevilla,»...por algunos días que se ocupó en adobar ciertas vedrieras y otras cosas como lo dió por una memoria» ${ }^{35}$; y lo mismo hallamos en la catedral de Oviedo en la que consta que el 7 de septiembre de 1580 aparece un vidriero "...que se ofreçe a adereçar las vidrieras y haçer otras de nuevo si fuere menester conforme a un memorial que mostró de lo que hera neçesario y costaría» ${ }^{36}$. Esta memoria no siempre era hecha por el maestro al que se pensaba encargar la realización de las vidrieras. A veces, era un trabajo independiente que se encargaba con el fín de disponer de una información precisa sobre los precios llegado el momento de proceder a la contratación de las vidrieras de un edificio. Cuando se pensó realizar las vidrieras de la catedral Nueva de Salamanca, se llamó de Burgos al vidriero Juan Guerra, en 1555, para que realizase un presupuesto de lo que podían $\operatorname{costar}^{37}$.

En el proceso de contratación hubo dos factores determinantes: Ia información acerca de los precios recabada por los comitentes y el conocimiento que tenían los talleres, tanto españoles como extranjeros, acerca de qué edificios necesitaban continuar un programa de vidrieras, reparar de las existentes o realizar otras nuevas. El carácter itinerante de la labor de muchos vidrieros se explica por este conocimiento de la demanda producida por las obras en curso. La circulación y movilidad de los talleres obedecía por lo regular a unas motivaciones y unos mecanismos concretos que permiten, en numerosos casos, explicar las causas de este trasiego. La selección de los talleres, realizadas muchas veces, como sucede en España a mediados del siglo XVI, por razones económicas, estuvo condicionada en muchas ocasiones por la puntual información acerca de los precios que poseían los cabildos. Cuando el cabildo de la catedral de Salamanca, tras varios intentos fustrados con talleres españoles para realizar las vidrieras de la catedral decidió "...que se truxesen de flandes atento a que seran más baratas" ${ }^{38}$ se ponía claramente de manifiesto la existencia esta información que circulaba entre los cabildos.

Antes de emprender un programa de vidrieras era frecuente buscar información y acudir a centros en los existian un conjunto importante

Nieto Alcaide, V., 1969, Doc. IV, 45, pág. 214.

25 Caso Fernandez. F. De, Colección documental sobre la catedral de Oviedo // (1520-1599). Gijón, 1983, Doc. 312, pág. 163.

5: Asi consta en un pago del 21 de agosto de 1551, Sanz Mariinez, J., "Las vidrieras de la Catedral Nueva de Salamanca". Archivo Español de Arte y Arqueologia. 1933, pág. 58.

33 Sanz Martinez, J., 1933, pág. 55. 
para tomarlos como punto de referencia. Estas consultas condicionaron en muchos casos la contratación de los vidrieros para la realización de los nuevos programas. El 10 de junio de 1508, el Cabildo de la catedral de Oviedo daba poder "al señor bachiller Juan de San Juan, canónigo e administrador de la fábrica desta dicha iglesia, para que en su nombre de la dicha iglesia e fábrica della vaya a la ciudad de León e allí, ynformado de personas peritas en la obra de vidrieras, faga asiento e iguale con Diego de Santillana e con cualesquier otras personas sobre las vidrieras para esta santa Iglesia. neçesarias, asy en la cantidad como en la calidad dellas, e sobre los preçios de ellas e de los maestros que oviere de aver e los plasos e terminos que le paresçieren ayan de ser fechas e asentadas en preçio e para la paga de los maravedis que ovieren de haber, en los colores, rostros e figuras dellas" ${ }^{39}$. Tradicionalmente, León aparece como un paradigma y un modelo. En el contrato que realizan Arnao de Flanes y Juan de Valdivieso el 6 de septiembre de 1503 para realizar las vidrieras del crucero de la catedral de Palencia se acuerda se dice que para confirmar el precio se busque información en las catedrales de Ávila, Burgos o León "o de otra qualquier yglesia donde semejantes obras se han hecho por los dichos Valdivieso y Arnao" " ${ }^{40}$. Junto a León, desde finales del siglo XV, Burgos se había convertido en un centro prestigioso bien conocido, hasta el punto de que, cuando se piensa asentar el programa de las vidrieras de la catedral de Segovia, se comisionó el 2 de abril de 1543 al fabriquero Juan Rodriguez "para ir a Burgos y otras iglesias para ver las vedrieras" ${ }^{41}$.

Respecto a los vidrieros, los encargos venían por mediación de otros talleres con los que tenían relación o a través de la información que facilitaba el conocimiento de la demanda surgida en determinados edificios. El encargo que se hizo a Arnao de Vergara para realizar una vidriera en la catedral de Segovia se debió a la mediación de su hijo Nicolás de Vergara que habia comenzado a realizar vidrieras para esta catedral. Pero tampoco faltan ejemplos en los que los encargos venían determinados por los gustos y criterios de selección de un mecenas, como es el caso del vidriero Enrique Alemán, protegido del Cardenal Mendoza que realizó vidrieras en la catedral de Sevilla cuando Don Pedro ocupaba la mitra sevillana pasando a la de Toledo, poco después de que este prelado se

Caso Fernandez, F. De, 1982, Doc. 142, pág. 101.

Garcia Cuesta, T., 1959, Doc. 2, pág. 77.

Archivo de la Catedral de Segovia. Libro de Fábrica de 1542-1562. Sin foliar. Descargo de 1543 
trasladase a la primada, y realizando vidrieras para el Colegio de Santa Cruz de Valladolid construido por este mecenas.

En los encargos jugó tambien un papel importante la mediación de otros artistas, como los maestros de obras y los arquitectos. Para el encargo de las vidrieras de la catedral de Oviedo, por ejemplo, debieron mediar Juan de Badajoz el Viejo, que estaba al cargo de las obras de la catedral, y su oficial, Pedro de Buyeres, maestros que habian trabajado en la construcción Librería de la catedral de León para la que tambien Diego de Santillana había realizado las vidrieras ${ }^{42}$. Y lo mismo sucede con Arnao de Vergara que conocía a Siloé desde sus años burgaleses y que fue probablemente quién le facilitó trabajo en Granada. Al menos, en esta ciudad le hallamos realizando, con Juan del Campo, vidrieras para la iglesia de San Jerónimo a cuyo cargo estaba Siloé. Igualmente, la intervención de Juan del Campo en las vidrieras de este edificio y en la catedral de Granada se debería a la mediación de Siloé a cuyo cargo estaban tambien ambos edificios ${ }^{43}$.

Algunos testimonios ponen de manifiesto que en determinados talleres existían relaciones y compromisos orientados a acaparar los principales encargos. En los procesos de tasación, acto previo al pago de la obra, es fácil rastrear las amistades y aversiones, los enfrentamientos y la coordinación existente entre los distintos vidrieros y talleres. Cuando Teodoro de Holanda, vidriero que había ofrecido realizar las vidrieras de la catedral de Granada más baratas y de mejor calidad que las que acababa de poner Juan del Campo, llega con las vidrieras, encuentra una crítica hostil por parte de este vidriero y Machuca. Ante la persistencia en esta actitud, el 21 de mayo de 1557, pedía licencia upara asentar las vedrieras que él trayra de Salamanca un arytifice que diga lo que son las vedrieras y que si dixese que no son tales como él está obligado, que a su costa las quitará" ${ }^{44}$. Este vidriero no era otro que Enrique Broecq que se encargaba de las vidrieras de la catedral salmantina. Lo que pone de manifiesto como, entre los vidrieros flamencos que aparecen a mediados del siglo xVI en España existía una cierta coordinación ${ }^{45}$.

Caso Fernandez., F. De, 1981, págs. 303-304.

Niero Alcallt. V.. Corpus Vitrearum Medii Aevi. España Vol. II. Las vidrieras de la catedral de Granada. Granada. Universidad de Granada. 1973, pág. 28 y ss. Nieto AlCAIDE, V., Arnao de Vergara. Sevilla. Diputación Provincial. 1974, pág. 25. NIE. TO ALCAIDE, V. "Juan del Campo: las vidrieras de San Jerónimo de Granada", Boletín Auriense, 1975, págs. 381-386.

Nieto Alcaide, V., 1973.. Doc. 22, pág. 309.

45 Nifto Al.cAide, V. "La vidriera Manierista en España: Obras importadas y maestros proce dentes de los Paises Bajos (1543-1561)", Archivo Español de Arte, 1973, pág. 107. 


\section{LAS OBRAS Y LOS CONTRATOS}

La labor de los vidrieros abarcó diversos trabajos claramente diferenciados como la realización de una obra o un programa, la reparación de vidrieras preexistentes o el ejercicio del cargo de vidriero de una catedral que incluía la realización de vidrieras nuevas y el arreglo y mantenimiento de las existentes. A este respecto, todos los contratos que conocemos de los siglos $X V$ y $X V I$ coinciden en lo esencial. El contrato realizado entre el Cabildo de la catedral de León y el Maestro Valdovin el 24 de abril de 1441 recoge unas condiciones similares a las que hallamos en otros posteriores. Además de casa y siete cargas de trigo al año, se le pagarían 13 maravedis por cada día que trabajase (y 16 en verano), suministrándosele la leña para labrar ${ }^{46}$. En relación con el cargo de vidriero en una catedral, el contrato celebrado el 22 de diciembre de 1534 entre Arnao de Flandes y Arnao de Vergara formando compañia y el cabildo de la catedral de Sevilla, constituye un testimonio preciso ${ }^{47}$. Los dos vidrieros se comprometían a realizar todas las vidrieras que les fueran encargadas según una muestra previa en la que se indicarían los colores y en la que el cabildo podía hacer las observaciones oportunas "con que sea cosa que en vydrio se pueda hazer». Dicha muestra, una vez firmada, sería realizada con el mejor amarillo de plata y atendiendo a que «la pintura que encima se pusiere sea muy bien recocida" Los vidrios deberían tener la misma calidad, claridad y grosor que la muestra. Antes de su asentamiento se revisarian para confirmar si se hallaban conforme a la muestra y de estarlo se mandaria asentar y si no que vuelvan a hacer a su costa lo que no sea conforme. El salario anual era de trescientos ducados, cien a la firma del contrato para adquisición de materiales y, luego, cincuenta cada tres meses a condición de haber asentado una vidriera en ese tiempo, de forma que al año estuvieran asentadas cuatro. Caso de no haber asentado una cada tres meses quedarian exentos de pago, si bien si en tres meses asentaban dos, en los otros tres meses se les efectuaría el pago. En cambio, si no pudieran trabajar por falta de materiales, se les daría un ducado diario. El precio se fijaba a tres reales y medio el palmo que era la forma habitual de tasar, sin recibir nada más por las muestras, cartones y el asentamiento.

Las condiciones de trabajo de los vidrieros permanecieron prácticamente inalterables cambiando los precios por palmo de vidrio puesto según las oscilaciones de los precios. En el siglo XVI, este problema se re-

Merino Rubio, W., 1974, pág. 372.

Nieto Alcaide, V., 1969, Doc. IV, 18, pág. 209. 
fleja de forma acuciante debido a la inflación y al hecho de que el vidrio se importaba de Flandes. Una petición de aumento de salario realizada por Arnao de Flandes el 8 de agosto de 1552 pone de manifiesto este problema. Entre las razones que da para justificar su petición Arnao de Flandes indica como "...todas las cosas han subido y ansy mesmo los materiales de mi arte especialmente agora que se han ofreçido estas guerras porque se traen de la alta borgoña" ${ }^{48}$.

El problema del precio del vidrio fue uno de los factores determinantes de los costos de las vidrieras cuya forma de pago se hacia por pie o palmo de vidrio puesto y cuyo precio variaba según fuera blanco o pintado. En un contrato entre Juan de Valdivieso y Arnao de Flandes con el cabildo de la catedral de Palencia se acordaba pagar el pie a 100 maravedis "contando el pie a uso de maestros de su oficio" ${ }^{49} \mathrm{En}$ algún caso, como en el contrato de Diego de Santillana con el Cabildo de la catedral de Palencia, se estipuló que el precio del palmo se entiende «medido por la medida del marco de Burgos, como en lo semejante se suele hacer" ${ }^{50}$. En el inventario de los bienes de Nicolás de Vergara realizado el 10 de noviembre de 1574 figuraba entre los utensilios y herramientas existentes en su obrador palmos de "hierro de medir» ${ }^{51}$.

En el proceso de realización de una vidriera el pago de los cartones quedaba incluido, a veces, en el precio convenido. Sin embargo, no faltan ejemplos en los que se pagaba aparte como los que serían necesarios para las vidrieras de la capilla Mayor de la catedral de Granada encargados a Juan del Campo ${ }^{52}$. Los documentos relativos a la contratación y pagos de vidrieras raramente se salen de este procedimiento: contratación, comprobación de que el trabajo realizado reunía las condiciones y pago según lo estipulado por cada medida de vidrio puesto. No obstante las condiciones podian variar según fuera con sus redes y con el hierro y andamios a cuenta del cabildo. En algún caso, aunque esto fue excepcional, se dió una gratificación al vidriero, se aceleraron los pagos, debido a la diligencia y prontitud con que había llevado a cabo su labor. Es el caso, de Diego de Santillana a quien, el 19 de octubre de 1509, el cabildo de la catedral de Oviedo decide darle, además de lo estipulado en el contrato, "...otros veynte mill maravedis por rason que se daba diligençia en la obra e toda presteza" ${ }^{53}$.

Nieto Alcaide, V., 1969, V, Doc. 115, pág. 225.

Garcia Cuesta, T., 1959, Doc. 2, pág. 77.

Garcia Cufsia, T.. 1959, Doc. 4, pág. 80.

MARIAS, F., 1983, I pág. 364.

Nie to Alcaide, V., 1973, Doc. 37, pág. 311.

Caso Fernandez, F. De, 1982, Doc. 145, pág. 103. 
Uno de los trabajos que se realizaron de forma continuada en relación con las vidrieras fue, como pone de relieve el estudio de las obras mismas, el de su reparación y conservación. Las vidrieras por su fragilidad, por hallarse expuesta a la intemperie y por su estructura, formada por piezas de vidrio unidas por plomos, requerían un mantenimiento constante. En Burgos, en 1569, con motivo de la bendición de la bandera de la compañia de Don Sancho de Tovar destinada a combatir a los moriscos de Granada, las salvas de arcabuceria cesaron al llegar a la puerta de la catedral "por el peligro que había de quebrarse y caherse las bedrieras della..." ${ }^{54}$. Un vidrio partido o roto provocaba al poco tiempo una perdida acelerada de las distintas piezas del panel. A eso se refiere una cláusula del contrato que celebra Arnao de Flandes el 24 de noviembre de 1543 para mantener las vidrieras de la catedral de Sevilla, en la que el vidriero se compromete "a tenerlas reparadas de manera que en ellas no aya agujero ninguno" 55 . Y lo mismo sucedía cuando entramado de plomos dejaban de cumplir su función de sujeción. Por ello, fueron frecuentes los reemplomados de algunos paneles como acreditan numerosas menciones documentales ${ }^{56}$. En la catedral de Oviedo, cuyas vidrieras se habían concluido en 1510, se contrataba ya su reparación el 3 de octubre de $1526{ }^{57}$. En la catedral de León, el 4 de febrero de 1508, con motivo de discutirse el salario de Diego de Santillana por realizar esta labor, ante la negativa de algunos canónigos, el administrador indicó que si “... se cayesen vidrieras algunas e se hiciese más estrago en ellas del que tenian de que avia muy eminente neçesidad de reparo que fuere en cargo de los dichos señores"., aprobandose "pues era utilidad e provecho grande de la dicha iglesia e fábrica" "SB. Lo primero que se le ordenó a Carlos de Brujas cuando fue nombrado maestro de vidrieras de la catedral de Sevilla el 8 de agosto de 1558 fue que "empiece a las reparar" ${ }^{59}$. De ahí, que los vidrieros encargados de realizar las nuevas vidrieras de una catedral tuvieran a su cargo el mantenimiento de las existentes. Con írecuencia, las reparaciones realizadas poco después de la ejecución y con unos mismos planteamientos estilísticos, se integraron en el estilo de la vidriera. Durante la Edad Media y el Renacimiento las reparaciones fueron llevadas a cabo por artistas de prestigio y no por simples reparadores. Arnao de Flandes

Lonez Mata, T.. La catedral de Burgos. Burgos. 1950.

Nieto Aicaide, V., 1969, Doc. V. 28, pág. 219.

Nieso Al Calde, V., 1969, Doc. V. 177 196. págs. 230-231; Doc. VI. 13, pág. 233. : Doc. VII.

52,58 pág 240

Caso Fernandez, F. De, 11, Doc. 207, pág. 34

MF rino Rubio, W., 1974, pág. 362

Nitio AlCaild, V., 1969. Doc. VI. 11. pág. 233 
tenía, por ejemplo, salario para la conservación de las vidrieras de la catedral de Sevilla. Este vidriero, el 24 de noviembre de 1543, firmaba un contrato por «entender en los reparos de las vedrieras» 60 . No fue hasta la segunda mitad del siglo XVI cuando el cargo de vidriero en una catedral pasó a consistir exclusivamente en la reparación de lo existente.

Para estas labores de conservación también se llamó ocasionalmente a vidrieros que realizaron trabajos puntuales en aquellos edificios en los que no existía un artista con el cargo de vidriero. Este tipo de trabajos debió de ser habitual en los siglos XIII y XIV, aunque las menciones documentales sean escasas y no comiencen a abundar hasta la centuria siguiente. A veces, la labor consistía solamente en "visitar» las vidrieras de un edificio para revisarlas, como cuando en 1452 se pagó al Maestro Juan, vidriero de Burgos, por haber ido a la catedral de León a ver las vidrieras ${ }^{61}$. En otros casos se contraba a un maestro para efectuar reparaciones concretas. Así, por ejemplo el 21 de junio de 1501 se contrataba a Juan de Valdivieso, vidriero de Burgos, para la reparación de las vidrieras de la Capilla del Corpus Christi y de San Pedro de la Catedral de Palencia ${ }^{62}$.

Una situación intermedia entre el vidriero encargado permanentemente de la realización y conservación de las vidrieras de una catedral y los que eran contratados para realizar una reparación concreta, lo constituye la labor de algunos maestros contratados para atender el estado de las vidrieras con la obligación de residir en la ciudad solamente por algún tiempo. Es el caso, del contrato con Gonzalo Escalante del 4 de junio de 1565 para la conservación de las vidrieras de la catedral de León con un salario de 3000 maravedises anuales y con la obligación de residir en León tres meses al año ${ }^{63}$. También, otro procedimiento habitual consistió en desmontar las vidrieras o paneles dañados y llevarlos al taller de un vidriero para su reparación como las de la catedral de Cuenca que se llevaron a Burgos en 1628 para que las restaurase el maestro Valentín Ruiz ${ }^{64}$.

\section{LOS MATERIALES Y EL PROCESO DE EJECUCIÓN}

En el trabajo de los vidrieros los materiales han desempeñado siempre un papel primordial. En lo relativo a su adquisición la documentación es

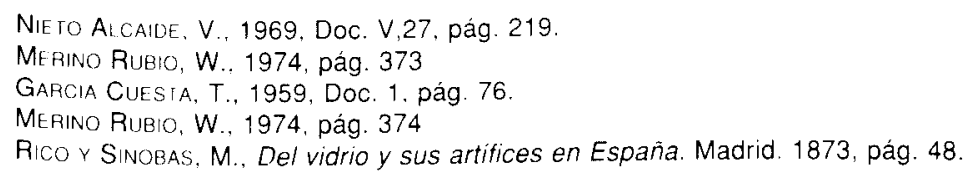


muy abundante. Uno de los problemas técnicos más importantes para la realización de las vidrieras era la resistencia de los vidrios. Una resistencia que se hallaba limitada por la exigencia de que tuviera una transparencia adecuada, pues, un vidrio excesivamente grueso, aunque fuera mucho más resistente, podía resultar de una traslucidez insuficiente. Cuando el 15 de julio de 1557 se examinan las vidrieras que Teodoro de Holanda había traído de los Paises Bajos para la catedral de Granada y que habian suscitado el mencionado problema de competencia con Juan del Campo, se reconoce «que el bidro es gordo y claro y bueno» 65 . Por lo regular, el vidrio utilizado para la realización de las vidrieras españolas ha sido casi siempre vidrio importado. En el contrato, realizado el 2 de septiembre de 1467 por Arnaldo de Morer con el cabildo de la catedral de Valencia se hace referencia a cuando "el vidrio haya llegado" (lo vidre sera vengut)

Lo más frecuente era que los vidrieros adquirieran el vidrio en el extranjero. En alguna ocasión fueron los mismos vidrieros los que fueron a comprarlo como Enrique Alemán a quién en el contrato de 1484 para realizar vidrieras para la catedral de Toledo se le comisiona para que vaya a Flandes o a cualquier otro sitio para comprar «...buen vidrio, asy blanco, como azul, verde colorado, amarillo o prieto de la groseza que llevare la muestra e trayga tanto de ello quanto sea menester e bastase para las ventanas e logares de la dicha sancta yglesia donde se ovieron de poner" 67 . En algún caso, incluso se exigía que el vidrio fuera de Flandes. En el contrato celebrado entre Nicolás de Vergara el Mozo el 7 de febrero de 1590 para realizar vidrieras para la catedral de Toledo se estipulaba "que todas las dichas vidrieras han de ser de vidrio pintado de flandes" "68. Sin embargo, lo más frecuente es que el vidrio se comprase en la ciudad o en las ferias por mediación de mercaderes. En este sentido, Burgos aparece con frecuencia como ciudad comercial en la que se adquirian vidrios importados de Flandes ${ }^{69}$. Para las vidrieras de la catedral de Gerona, el 14 de abril de 1385 se compraba una partida de vidrio que vino de Barcelona ${ }^{70}$, no sabemos si fabricado allí o importado.

Nieto Alcaide, V., 1973, Doc. 3. pág. 311

Esto que extrañó a SANCHIS Y SIVERA, J., "Vidrieria historiada medieval en la catedral de Valencia". Archivo de Arte Valenciano., 1918, Doc, VII, pág. 31, por existir vidrierias en Valencia, era una práctica habitual.

NiE IO AlCAide, V.. 1967, pág. 73.

Zahco df I Val.li, M. R., Datos documentales para la Historia del Arte Español. II. Documentos de la catedral de Toledo. Madrid. centro de Estudios Históricos. 1914, pág. 267.

Nif to Al calde, V., 1969. Doc. V', 12, pág. 217.

Ainaud de Lasafrie. J., y otros. 1987, pág. 35 
En el siglo xvi se registra con toda precisión la práctica de importar vidrio. Vidrio que estaba exento de impuestos como pone de manifiesto una petición de Juan del Campo con motivo de la compra de una partida para las vidrieras de la catedral de Granada. El 25 de agosto de 1556. este vidriero, para traer el vidrio que había llegado al puerto de Cádiz. solicitaba del cabildo que «...le diesen una cédula que hay en esta Santa Iglesia para que no se pague derecho del vidrio que es para las vedrieras de las Iglesias de Hespaña" "' Y lo mismo sucedía con las vidrieras importadas acerca de las cuales existen menciones que acreditan la existencia de una exención de impuestos. Teodoro de Holanda, el 4 de junio de 1557 solicitaba un "testimonio" de que las vidrieras que acaban de llegar eran para la catedral «para que conste asi a los arrendadores de los almoxarifazgos para que no lleven derechos de las dichas vidrieras"

El 17 de marzo de 1535, el mercader flamenco establecido en Sevilla, Jos Rras. vendía al vidriero Arnao de Vergara "ochenta liaños de vidrio para facer vidrieras" que tenía en la villa de Bilbao. Su descripción es un claro ejemplo de la proporción de los colores utilizados por el vidriero en sus obras: "... los cinquenta e cuatro blancos y los veynte e seys de colo. res que se entiendan las colores diez liaños azules e seys de colorado e quatro verdes e dos de amarillo e dos azules claros e dos de morado púr. pura" ". En este sentido. es evidente que los vidrieros sufrian una dependencia en lo referente a la adquisición de los materiales para su especialidad. Un acuerdo de la catedral de Salamanca del 11 de agosto de 1556 resulta reveiador a este respecto al ordenarse que se "envie por vidrios y plomo e por todos los otros materiales que fueren necysario para las vedrieras a Flandes o donde fuere necysario" "Y Y lo mismo hallamos con respecto a otros materiales como los plomos que en algún momento escasearon $"$ La red de plomos era, sin duda, uno de los componentes que garantizaban la peremnidad de la vidriera. De ahí, las recomendaciones relativas a como deberian de ser como las que figuran en el contrato de 1484, entre Enrique Alemán y el cabildo du la catedral de Toledo, en las que se estipula que «... faga las canales de plomo bien fornidas. e sean

\footnotetext{
Nif Al Allt, V.. 1973 (1). Doc. 12. pag. 308

Ni: Al All, V. 1973. Doc. 23. pág. 309.

Nito Airall, V. 1969. Doc. IV. 22. pag. 211

SAn/ Mantint/. J. 1933, pág. 59.

En 1535 se pagaba a Arnao de Vergara «por cierto plomo que ltevo de la iglia para la v1. driera de San San Sebastian porque no lo hallaba en la ciudad". Nit if Al (Ali. V. 1969. Doc. IV
} 
altas de manera que abracen e se encaxe bien el dicho vidrio, para que sea durable, por causa de los ayres e vientos" ${ }^{76}$.

La realización de vidrieras comportaba, además, la ejecución de otros trabajos complementarios como la red de alambre que, desde los orígenes de la vidriera, era el único sistema utilizado para su protección exterior. No ha de extrañar por ello que en los contratos se incluyeran cláusulas orientadas a garantizar su resistencia y eficacia. En el contrato celebrado por Diego de Santillana con el Cabildo de la catedral de Palencia el 17 de diciembre de 1512 se estipulaba «...que ha de texer las redes bien espesas" 77 . En los contratos, las redes figuraban casi siempre como una parte inseparable de la vidriera que era realizada por los mismos vidrieros, con alambre que, en ocasiones, se compraba también en Flandes ${ }^{78}$ y cuyo importe se hallaba comprendido en el precio del palmo de vidrio puesto. En un pago realizado el 6 de marzo de 1562 a Juan del Campo en la catedral de Granada se indicaba que se le pagara "el palmo de las pintadas a tres reales y las blancas con las redes dellas a dos reales y medio" ${ }^{79}$.

La realización de una vidriera comportaba diversas operaciones que, con escasas variantes, se han mantenido inalterables desde sus orígenes y que han sido descritas sistemáticamente en los tratados: cartón a escala reducida o proyecto, cartón a escala 1:1, selección y corte de los vidrios, pintura de los vidrios, coción de la pintura al fuego, emplomado y asentamiento. En el Museo de Gerona se conserva una mesa de vidriero del siglo xiv con el diseño que sirvió de base para una de las vidrieras del presbiterio de la catedral ${ }^{80}$ y en la que puede apreciarse este sistema de trabajo que permaneció inalterable durante siglos y que ya nos es descrito por el Monje Teófilo en su tratado de hacia 1100 Schedula diversarum artium.

En los documentos se menciona el cartón, ya sea a escala $1: 1$ o a escala reducida, como patron. Este patrón era un diseño distinto de los dibujos preparatorios que en muchas ocasiones realizaban otros artistas. Esta participación de pintores fue frecuente aunque no constituyó una condición imprescindible. $Y$ tampoco faltan los testimonios que acreditan a los pintores realizando labores propias de los vidrieros como la reparación de vi-

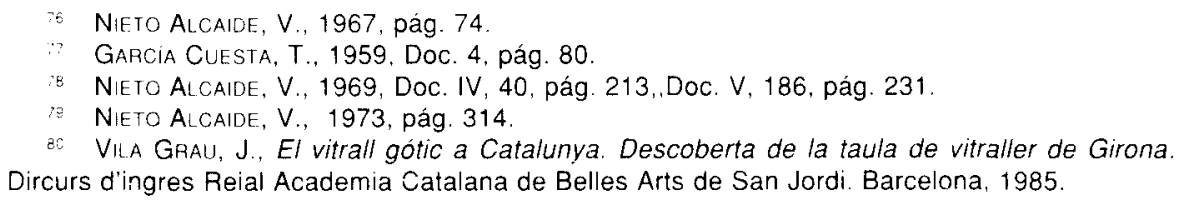


drieras. En 1380 el pintor Lluis Borrassá cobraba por la reparación de una vidriera del presbiterio de la catedral de Gerona ${ }^{81}$ y, en 1459, Maestre Nicolás Francés, que también proporcionó modelos para las vidrieras de la catedral de León, recibía un pago por haber puesto nueve piezas de vidriera en la capilla de San Sebastian de la catedral de León ${ }^{82}$. Sin embargo, la participación de artistas de otras especialidades en la realización de vidrieras se limitó casi siempre a la ejecución de los bocetos para el cartón a escala reducida. A este respecto es oportuno notar como el cabildo de la catedral de Granada, habiendo visto un patrón de una de las vidrieras que hace Juan del Campo dió orden para que «haga Siloé el debuxo de los patrones para las dichas vidrieras" ${ }^{83}$. Esta mención pone de relieve como el patron era algo distinto del proyecto o cartón a escala reducida e incluso de los dibujos que podian ser hechos por los vidrieros como en el mencionado caso de la muestra que figura en el citado contrato de Arnao de Vergara y Arnao de Flandes de 1534. Este trabajo, a veces, se pagaba a parte como cuando el 4 de abril de 1515 se ordena pagar a Juan Jacques por « 8 días que debujo la obra en papel de las vidrieras» ${ }^{84}$, lo cual pudo ser el cartón a escala reducida o el paso de este al cartón a escala natural. Sin embargo, lo más frecuente era que el precio de los cartones se incluyese en el coste total de la vidriera como consta en el mencionado contrato de Arnao de Vergara y Arnao de Flandes con el Cabildo de la catedral de Sevilla en el que se estipuló «que por los patrones o muestras que hisiere ny encasamientos ni por asentar las dichas vedrieras no se les a de dar cosa ninguna más de los tres reales y medio por palmo» ${ }^{85}$.

Con frecuencia los vidrieros utilizaron unos mismos cartones para realizar vidrieras en diferentes edificios. En el inventario de los bienes de Nicolás de Vergara, realizado en 1574 consta la existencia de varios cartones preparatorios ${ }^{86}$. La colección de cartones y dibujos, al igual que más adelante la de estampas, fue algo habitual desde los primeros tiempos de la vidriera. El hecho de que el cartón solamente fuese el modelo permitió a los artistas utilizar composiciones o figuras ya realizadas en las vidrieras de un edificio para las de otro. En la vidriera española la utilización de unos mismos cartones fue una práctica frecuente según prueban diferentes ejemplos conocidos. Enrique Alemán utilizó para las vidrieras

\footnotetext{
Ainalud de Lasakte, J., y otros, 1987, Doc. 18, pág. 35.

Merino Rubio, W. 1974, pág. 374

Nieto Alcaide, $V .$, 1973, Doc. 5, pág. 313

Nieto Al caide, V., 1969. Doc. IV, 18, pág. 210

Nieto Alcaidf, V.. 1969, Doc. IV, 18, pág. 210

Marias. F., I. 1983, pág. 364.
} 
que realizó en la catedral de Toledo entre 1487 y 1488 los mismos cartones que habia empleado en las de la catedral de Sevilla ejecutadas poco antes entre 1478 y $1479{ }^{87}$; Diego de Santillana usó los mismos cartones en las vidrieras de la Librería de la catedral de León que en las que realiza poco después en la catedral de Oviedo ${ }^{88}$ Y el mismo sistema siguió Juan del Campo en las vidrieras que realizó para la iglesia del Monasterio de San Jerónimo y para la catedral de Granada ${ }^{89}$.

En la ejecución de las obras el control de su calidad fue una preocupación constante de los comitentes que se refleja en las numerosas cláusulas de los contratos dispuestas al respecto. Además de la calidad artística de la vidriera se atendió, también, a la de los materiales empleados. Para ello, el sistema utilizado consistía en que el vidriero entregase una muestra con la finalidad de poder comprobar que la obra, una vez terminada, se ajustaba a ella. Dicha muestra era de diferentes tipos. Una de ellas consistía en hacer un cartón a escala reducida o proyecto. En el contrato que suscriben Arnao de Vergara y Arnao de Flandes con el cabildo de la catedral de Sevilla el 22 de diciembre de 1534 ambos maestros se comprometian a cque antes que nynguna de las dichas bidriras se ponga en obra de vidrio se haga una muestra de la ystoria y ymagenes que vuestra señoria señalare en cantidad de medio pliege de papel de marco maior declarado lo mejor que nosotros pudieramos y en ella declarado todo de amarillo que paresca ser menester, para ser la obra más rica y las otras colores se repartan muy por concierto al tiempo que la vidriera se ponga en obra muy por concierto según se requiere a la ystoria y ymagenes que se hyzieren. $Y$ hecho el deseño y muestra, que por vuestra señoria nos fuere mandado hazer, y acabado y apartado lo que ha de ser de amarillo, la qual color al tiempo que se haga en la vidriera ha de ser mas que menos, le traiga uno de nosotros y entramos ante los señores diputados para que lo vean y visto y añadiendo y quitando lo que les pareciere por escrito a las espaldas de la dicha muestra lo asyenten con que sea cosa que en vydrio se pueda azer y contentos io firmen de sus nombres. $Y$ asi firmados la dicha muestra de los señores diputados se comienze y acabe de sus vidrios conforme a la muestra que asy estuviere firmada de muy finas colores y que las colores sean del mesmo vidrio asi el colorado como el azul y el verde y el amarillo y el violeta y el morado y el blanco y el amarillo que se haze en

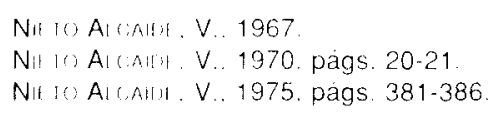


nuestro horno sea de muy buena plata, limpia y acendrada para que tenga mejor lustre y color [y que] los dichos vidrios, que asi se pusieren en las dichas vidriras, sean conforme a las muestras de vidrio que el señor mayordomo tiene en su poder y que antes sean mejores que no peores...». En algún caso esta muestra es probable que fuera una vidriera de pequeñas dimensiones como la que se acuerda, el 6 de junio de 1526, que haga Arnao de Vergara, indicandole que sean"de mejor color, gordor e imágenes que las otras que fiso para el zimborio e que sean de buen tamaño» 90 .

Los vidrieros realizaron siempre sus obras para unos ventanales dados, sino que, en algunos edificios, tuvieron una intervención directa en la forma de resolver y realizar las tracerías y la composición de los ventanales. En algunos edificios, como la catedral de Segovia, el trazado de los ventanales se realizó pensando en su programa de vidrieras. Cada ventanal se trazó con tres vanos, el central de mayores dimensiones, para desarrollar un programa tipológico con una escena del Nuevo Testamento en el central y los precedentes del Antiguo Testamento en los laterales. Es seguro. dado que desde el comienzo de las obras el fabriquero disponía de una traza con ei programa iconográfico de las vidrieras, que esta composición de los ventanales se hizo pensando en las vidrieras que se habrian de colocar ${ }^{\prime}$. En otros casos fueron los mismos vidrieros los encargados de realizar las tracerías de los ventanales como se desprende del contrato, suscrito entre Arnao de Vergara y Arnao de Flandes y el cabildo de la catedral de Sevilla, en el que se estipula que si alguno de los dos vidrieros "nos ocuparemos en traçar algunas claravoias y maineles asy de piedra como de yesos den al que de nos se ocupare dos reales cada dia» 92 .

Uno de los problemas, acerca del cual tenemos abundantes, noticias era el de los andamios necesarios para proceder a su asentamiento. Las constantes referencias documentales ponen de manifiesto que los andamios fueron un problema constante para el asentamiento de las vidrieras. Con frecuencia, los andamios que se montaban para tomar medidas permanecian instalados durante el tiempo de ejecución de las vidrieras para que pudieran ser utilizados para su asentamiento. Asi se desprende de una orden del 22 de diciembre de 1534, dada por el cabildo de la catedral

Nif i) Ai Mul. V.. 1969. Doc. IV. 7 y 8. págs. 207.209

Nit io Airily. $V$. "La iconografia de las vidrieras de la catedral de Segovia". en Miscelánea de Arte. Homenaje a Angulo Iñiguez. Madrid. C S.I.C. 1982. pags. 104-107.

Nit to Al crut. V. 1969. Doc. IV. 18. págs 209-210 
de Sevilla al mayordomo de fábrica para que «...mande azer los andamios firmes y seguros asi para tomar las medidas como para asentar las dichas bydrieras" ${ }^{93}$. Dicho procedimiento era lógico si se tiene en cuenta que un andamiaje sólo servía para asentar una o dos vidrieras o, como mucho, cuatro, y que, por ello, era un trabajo que los vidrieros podian ejecutar en poco tiempo. El problema se debía a que el montaje de los andamios constituía un coste adicional que corría de parte del comitente. En el contrato celebrado el 6 de septiembre de 1503 entre Juan de Valdivieso y Arnao de Flandes para realizar vidrieras en el crucero de la catedral de Palencia, se acuerda que «...que les hagan y den hechos todos los andamios para la obra" ${ }^{94}$. Y lo mismo hallamos en el contrato de Diego de Santillana para realizar tres vidrieras para esta misma catedral, según el cual el Cabildo se comprometía "de hazer e deshazer los andamios buenos e firmes a contentamiento del dicho Santillana" ${ }^{95}$. Dicho sistema se mantuvo como una práctica habitual; en 1538, en el contrato de Arnao de Flandes hijo para realizar vidrieras de la catedral de Sevilla se especifica que «el mayordomo ques o fuere haga hazer los andamios que fuesen menester ${ }^{96}$.

Los esfuerzos por ahorrar el coste adicional que suponía el andamiaje necesario para la colocación de las vidrieras condicionaron en ocasiones, el momento de asentamiento y realización de las vidrieras con el fín de aprovechar los andamios que estaban puestos para las obras. Por un acuerdo del 13 de mayo de 1558, el cabildo de la catedral de Granada decidía proceder a la colocación de las vidrieras por hallarse concluida la cúpula de la capilla mayor "...y por estar los andamios hechos, sería después inconveniente ponerse ${ }^{97}$. $Y$ en algún caso, los andamios que estaban instalados llegaron a condicionar la fecha de ejecución de las vidrieras. En el el contrato celebrado el 31 de mayo de 1512 para la realización de las vidrieras del Monasterio de San Francisco de Palencia con Diego de Santillana, se especifica que las vidrieras tendrían que estar concluidas para septiembre de ese año. Los comitentes pretendian aprovechar los andamios que estaban puestos estipulándose que las vidrieras «...sy después del plaço vinieren e fueren desechos los andamios, que agora estan para hazer la capilla, que el dicho Santillana los haga a su costa» ${ }^{98}$.

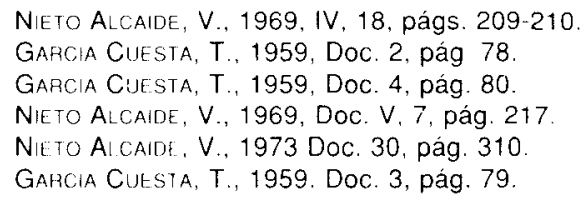

